\title{
Impact of social deprivation, demographics and centre on HbA1c outcomes with continuous subcutaneous insulin infusion
}

DOI:

10.1111/dme.13833

\section{Document Version \\ Accepted author manuscript}

Link to publication record in Manchester Research Explorer

Citation for published version (APA):

Paisley, A. N., Beynon, J., Fullwood, C., Hindle, A., Alam, T., Urwin, A., Chapman, A., Morris, J., Thabit, H., Rutter, M. K., \& Leelarathna, L. (2019). Impact of social deprivation, demographics and centre on HbA1c outcomes with continuous subcutaneous insulin infusion. Diabetic medicine: a journal of the British Diabetic Association, 36(3), 383-387. https://doi.org/10.1111/dme.13833

\section{Published in:}

Diabetic medicine: a journal of the British Diabetic Association

\section{Citing this paper}

Please note that where the full-text provided on Manchester Research Explorer is the Author Accepted Manuscript or Proof version this may differ from the final Published version. If citing, it is advised that you check and use the publisher's definitive version.

\section{General rights}

Copyright and moral rights for the publications made accessible in the Research Explorer are retained by the authors and/or other copyright owners and it is a condition of accessing publications that users recognise and abide by the legal requirements associated with these rights.

\section{Takedown policy}

If you believe that this document breaches copyright please refer to the University of Manchester's Takedown Procedures [http://man.ac.uk/04Y6Bo] or contact uml.scholarlycommunications@manchester.ac.uk providing relevant details, so we can investigate your claim.

\section{OPEN ACCESS}




\title{
Impact of Social Deprivation, Demographics and Centre on HbA1c Outcomes with Continuous Subcutaneous Insulin Infusion
}

\author{
Angela N Paisley ${ }^{1}$, Jennifer Beynon ${ }^{2}$, Catherine Fullwood ${ }^{3,4}$, Andrew Hindle $^{5}$, Tayiba Alam ${ }^{5}$, \\ Andrea Urwin ${ }^{6}$, Alyson Chapman ${ }^{6}$, Juliet Morris ${ }^{6}$, Hood Thabit ${ }^{6,7}$, Martin K Rutter ${ }^{6,7}$, \\ Lalantha Leelarathna ${ }^{6,7}$ \\ ${ }^{1}$ Salford Royal NHS Foundation Trust, Salford, UK \\ ${ }^{2}$ University Hospital of South Manchester, UK \\ ${ }^{3}$ Research and Innovation, Manchester University NHS foundation Trust, Manchester Academic \\ Health Science Centre, Manchester UK, \\ ${ }^{4}$ Centre for Biostatistics, University of Manchester, Manchester, UK \\ ${ }^{5}$ The School of Medical Sciences, University of Manchester, Manchester, UK \\ ${ }^{6}$ Manchester Diabetes Centre, Manchester Royal Infirmary, Manchester University NHS Foundation \\ Trust, Manchester UK \\ ${ }^{7}$ Division of Diabetes, Endocrinology and Gastroenterology, University of Manchester, Manchester, UK
}

$A P * J B$ are joint first authors of this work

\section{Correspondence}

L. Leelarathna, PhD

lalantha.leelarathna@mft.nhs.uk

\section{Article Type: Short Report}

Word count: Main text: 1824 Abstract 263: Tables 2:

Funding: Manchester Academic Health Science Centre

\section{Novelty Statement}

- Continuous subcutaneous insulin infusion (CSII) is often considered the 'gold standard' method of insulin replacement therapy for individual with Type 1 diabetes

- This is the first UK study to specifically report on the interaction of social deprivation, demographics and centre on pre-and post CSII HbA1c levels.

- Those with higher social deprivation and women had higher baseline HbA1c levels. However, the benefits of CSII therapy were not found to be associated with social deprivation or demographics, but only with pre-CSII HbA1c and centre. 


\section{Conflict of interest:}

LL reports having received speaker honoraria from Minimed Medtronic, Animas, Roche, Sanofi, Insulet and Novo Nordisk, serving on advisory panel for Abbott Diabetes Care, Roche, Sanofi, Minimed Medtronic, Animas and Novo Nordisk, grants to attend educational meetings from Sanofi, Dexcom, Novo Nordisk and Takeda. MKR has acted as a consultant for GSK, Roche and MSD, and participated in advisory board meetings on their behalf. MKR has received lecture fees from MSD and grant support from Novo Nordisk, MSD and GSK. AP, JB, $\mathrm{CF}, \mathrm{AH}, \mathrm{TA}, \mathrm{AU}, \mathrm{AC}, \mathrm{JM}, \mathrm{HT}$ report no conflict of interest. 


\begin{abstract}
Aims:

To assess the impact of social deprivation, demographics and centre on $\mathrm{HbA} 1 \mathrm{c}$ outcomes with continuous subcutaneous insulin infusion (CSII) in adults with type 1 diabetes.

\section{Methods:}

Demographic data, postcode-derived English Index of Multiple Deprivation data and 12 month average $\mathrm{HbA} 1 \mathrm{c}(\mathrm{mmol} / \mathrm{mol})$ pre- and post-CSIl were collated from three diabetes centres in the North West UK region, University Hospital of South Manchester (UHSM), Salford Royal Foundation Hospital (SRFT) and Manchester Royal Infirmary (MRI). Univariable and multivariable regression models explored relationships between demographics, Index of Multiple Deprivation, centre and HbA1c outcomes.
\end{abstract}

\title{
Results:
}

Data were available in $693(78 \%)$ individuals (centres UHSM, SRFT \& MRI: $n=90,112$ and 491 respectively); 59\% women; age at CSII start: median 39 (IQR 29.5-49.0) years; diabetes duration: 20 (11-29) years; Index of Multiple Deprivation: 15,193 (6,313-25,727). Overall HbA1c improved from $69(8.5 \%)$ to $64(8.0 \%) \mathrm{mmol} / \mathrm{mol}$ (median) within the first year of CSII. In multivariable analysis, higher pre-CSII HbA1c was significantly associated with higher deprivation $(p=0.036)$, being female $(p<0.001)$, and centre MRI $(p=0.005)$. Following pre-CSII $\mathrm{HbA} 1 \mathrm{c}$ adjustment, post-CSII HbA1c or HbA1c change were not related to demographic factors and deprivation, but remained significantly related to the centre; UHSM \& SRFT had larger $\mathrm{HbA} 1 \mathrm{C}$ reductions with CSII, compared to MRI (median -7.0 [-0.6\%] vs. $-6.0[-0.55 \%]$ vs. $-4.5[-0.45 \%] \mathrm{mmol} / \mathrm{mol} \mathrm{p}=0.005)$.

\section{Conclusions:}

Higher pre-CSII HbA1c levels were associated with higher deprivation and being female. CSII improves $\mathrm{HbA} 1 \mathrm{c}$ irrespective of social deprivation and demographics. Significant differences in $\mathrm{HbA} 1 \mathrm{c}$ improvements were still observed between centres. Further work is warranted to explain these differences and minimise variation in clinical outcomes with CSII.

Keywords: type 1 diabetes, continuous subcutaneous insulin infusion, insulin pump therapy 
Insulin pump therapy, also known as continuous subcutaneous insulin infusion (CSII), is considered the 'gold standard' of insulin replacement therapy for people living with Type 1 diabetes (T1DM) (1). Use of CSII has been shown to improve overall glycaemic control, as measured by $\mathrm{HbA1c}$, and reduce the burden of hypoglycaemia (2-4).

There is considerable variation in access to CSII in the United Kingdom (5). According to the National Insulin Pump audit of 2016/2017, the proportion of those with T1DM treated with CSII varies from less than $5 \%$ to more than $50 \%$ in participating centres. Notably, there is considerable variation in $\mathrm{HbA1c}$ levels achieved between individual centres, including the proportion of those with $\mathrm{HbA} 1 \mathrm{c}$ below $7.5 \%$ (59 mmol/mol) (from $17 \%$ to $69 \%$ ). Overall, approximately $15 \%$ of people living with type 1 diabetes in England are treated with CSII, but the proportions are lower in areas with higher deprivation (5).

Greater Manchester has a population of 2.8 million, with multi-ethnic and socially diverse groups. It is the first region in the UK to have a fully devolved health and social care budget, providing new opportunities to better serve the needs of the people living and working in the area (6). As recent national diabetes audits have shown variation of treatment target achieved, it is thus imperative to understand potential factors such as demographics and level of deprivation which may influence diabetes care and outcomes. Our objective was to compare and evaluate factors associated with changes in $\mathrm{HbA} 1 \mathrm{c}$ levels within a year of starting CSII between the three hospitals in the region, accounting for demographics and deprivation measured with the postcode derived English Index of Multiple Deprivation.

\section{Research Design and Methods}

Setting: We conducted this study at three Greater Manchester hospitals - University Hospital of South Manchester (UHSM), Salford Royal Foundation Hospital (SRFT) and Manchester Diabetes Centre, Manchester Royal Infirmary (MRI).

Design: Retrospective observational cohort study.

Inclusion criteria: We included individuals initiated on CSII therapy between the years 2000 and 2015 who had paired $\mathrm{HbA} 1 \mathrm{c}$ data.

Exclusion criteria: We excluded individuals whose CSII start date was unknown or those whose relevant pre/post-CSII data were unavailable.

Indication for CSII: In line with current national guidance, indications for CSII included poor glycaemic control, problems with hypoglycaemia, or glycaemic variability/erratic control.

Data collection: Demographic variables and $\mathrm{HbA} 1 \mathrm{c}$ data were obtained from electronic medical records at individual centres. $\mathrm{HbA} 1 \mathrm{c}$ data were collected from 12 months before and up to 12 months after initiation of CSII. The mean annual HbA1c (pre and post CSII) were used for all analysis. Typically, one to three $\mathrm{HbA} 1 \mathrm{c}$ tests were available per patient before and after pump 
start. We obtained the English Index of Multiple Deprivation 2015 for each participant's postcode from the Ministry of Housing, Communities and Local Government(7). The English Index of Multiple Deprivation is the official measure of relative deprivation for small areas in England and ranks these areas from 1 (most deprived area) to 32,844 (least deprived area). CSII training: There were differences in pre-CSII structured education participation in all three centres. Approximately $84 \%$ and $53 \%$ of individuals in UHSM and SRFT respectively had completed the Dose Adjustment for Normal Eating (DAFNE) structured education course prior to starting CSII, whilst $20 \%$ in MRI had participated in a local structured education course. The remaining individuals in MRI received individualised training lasting 1 to 3 hours, which encompassed carbohydrate counting and other aspects of diabetes self-management, before commencing CSII therapy. In all three centres, a CSII training session lasting 3 to 4 hours, which included sick day rules and technical trouble shooting, was provided to all individuals. Established methods were applied to set initial basal rate settings (i.e. 70 to $80 \%$ of total daily dose on multiple daily injections, divided by 2 ).

Statistical analysis: Descriptive statistics were used to examine the demographics and $\mathrm{HbA} 1 \mathrm{c}$ levels (raw and change), alongside boxplots. Differences between centres were tested via Fisher's exact tests (discrete data) and Kruskal Walis tests, with a post-hoc nemenyi test applied to analyse for differences between the three centres.

Univariable and multivariable regression models (full models alone) were utilised to assess relationships between individual outcomes: pre- and post-pump $\mathrm{HbA} 1 \mathrm{c}$, change in $\mathrm{HbA} 1 \mathrm{c}$ and explanatory variables: age at pump start (years, standard and centred on the median), deprivation index (standard and centred on the median, scaled in units of $10^{-3}$ ), gender (baseline female) and duration of diabetes at pump start (years, standard and centred on the median).

All $p$-values are two-tailed and values less than 0.05 were considered statistically significant. All analyses were conducted in R version 3.2.4 [R Core Team (2016). R: A language and environment for statistical computing. R Foundation for Statistical Computing, Vienna, Austria.[URL: https://www.R-project.org/] 


\section{Results}

Pre and post $\mathrm{HbA} 1 \mathrm{c}$ data were available for 693 individuals (78\%). Demographics and HBA1c data for the whole cohort and individual centres are shown in Table 1. Significant differences in gender and deprivation index were noted between the three centres. Although the spread of deprivation was wide across all three centres, median deprivation index was lowest (highest deprivation) in MRI. Overall, HbA1c improved from median 69 (IQR 61-80) to $64(55-73) \mathrm{mmol} / \mathrm{mol},(8.5 \%$ to $8.0 \%)$ within 1 year of CSII. The percentage of individuals with $\mathrm{HbA} 1 \mathrm{c}$ level $\geq 69 \mathrm{mmol} / \mathrm{mol}$ (8.5\%) reduced from $51.7 \%$ pre-CSII to $34.5 \%$ post-CSII. Patients with poorer glycaemic control at baseline showed larger HbA1c improvements compared to those with lower HbA1c levels (Supplemental Fig 1).

In a multivariable regression model combining deprivation index, age, duration of diabetes and gender, higher pre-CSII HbA1c levels were associated with higher levels of deprivation $(p=0.011)$ and being female $(p=0.001)$. However none of the demographic variables remained significant for post-CSII HbA1c or HbA1c change, when pre-pump HbA1c levels were adjusted for.

In the unadjusted analysis, significant differences were found between centres in pre and post $\mathrm{HbA} 1 \mathrm{c}$ levels (Table 1). However the percentages of individuals achieving greater than $5 \mathrm{mmol} / \mathrm{mol}(0.5 \%)$ reduction in $\mathrm{HbA} 1 \mathrm{c}$ were similar across centres (UHSM: $67.8 \%$ vs. SRFT: 64.3 vs. MRI: $63.7 \%, p=0.783)$.

Centres UHSM \& SRFT were associated with lower pre-CSII HbA1c levels than MRI, even after adjusting for demographics and Index of Multiple Deprivation ( $p=0.015$ and 0.012 respectively). Similarly, UHSM \& SRFT demonstrated significantly lower post-CSII HbA1C levels ( $p=0.042$ and 0.004 respectively) and greater change in $\mathrm{HbA} 1 \mathrm{c}$ levels than MRI (median change $-7.0[-0.6 \%]$ vs. $-6.0[-0.55 \%]$ vs. $-4.5[-0.45 \%]$ respectively, $p=0.005)$, even after adjusting for demographics, Index of Multiple Deprivation and pre-CSII HbA1c levels.

Table 2 quantifies the covariate effects along with the adjusted overall $\mathrm{HbA} 1 \mathrm{c}$ changes from baseline. Change in $\mathrm{HbA} 1 \mathrm{c}$ levels post-CSII was significantly associated with baseline $\mathrm{HbA1c}$ and centre. The model suggests each one $\mathrm{mmol} / \mathrm{mol}$ higher baseline $\mathrm{HbA1c}$ level is associated with a $0.45 \mathrm{mmol} / \mathrm{mol}$ greater lowering in post-CSII HbA1c level. This translates to a HbA1c lowering of $29 \mathrm{mmol} / \mathrm{mol}(4.8 \%)$ for a woman from MRI with a pre-CSII HbA1c of 120 $\mathrm{mmol} / \mathrm{mol}(13.1 \%)$ when all other covariates are fixed at their sample median.

Out of the whole cohort $141(20 \%)$ had undertaken the Dose Adjustment for Normal Eating (DAFNE) course prior to starting on CSII. Those with DAFNE training had lower preCSII HbA1c; $67(58,73)$ vs $70(61,81), p=0.001[8.3 \%(7.5,8.8)$ vs $8.6 \%(7.7,9.6 \%)]$ and lower post-CSII HbA1c $60(54,68)$ vs $65(56,74)$, p<0.001 [7.6\% $(7.1,8.4)$ vs 8.1\% $(7.3,8.9]$, compared to those who had not done DAFNE. However once adjusted for pre-CSII HbA1c, 
deprivation index and centre, participation in DAFNE was not associated with pre, post or change in HbA1c with CSII. (Data not shown). 


\section{Discussion}

Our study shows that CSII improves HbA1c irrespective of social deprivation status and demographics, however variation in $\mathrm{HbA} 1 \mathrm{c}$ outcomes exists between different diabetes centres. The majority of individuals at UHSM \& SRFT had participated in a validated structured education programme (DAFNE) before starting CSII therapy. In the unadjusted analysis those who had done DAFNE had lower pre and post CSII HbA1c levels. However after adjusting for deprivation index, pre-CSII HbA1c and centre, participation in DAFNE was not associated with $\mathrm{HbA1c}$ differences. Overall improvements in HbA1c during our study are broadly in keeping with published literature from UK $(2 ; 8)$ and elsewhere (9). Notably our data also confirms other studies which showed larger HbA1c improvements in individuals with higher pre-CSII HbA1c values (3). In our study the number of individuals using CSII was considerably larger at MRI than UHSM and SRFT. At MRI approximately $44 \%$ of adults with T1D are treated with CSII, in contrast to UHSM and SRFT where $18-20 \%$ are treated with CSII. This may be due to some differences in the interpretation of CSII entry criteria or patient selection even amongst neighbouring Trusts. Impact of any differential interpretation of entry criteria or patient selection on $\mathrm{HbA} 1 \mathrm{c}$ outcomes remains unclear.

In a previous study of children and adolescents, a 500 patient higher centre size was associated with a 1.5 higher odds of CSII use in an analysis that adjusted for age, gender and diabetes duration. However, the authors of this paper found no correlation between the proportion of CSII users in each centre and $\mathrm{HbA} 1 \mathrm{c}(r=-0.26, p=0.084) .(10)$

We also used National Diabetes Audit, Insulin Pump Report 2016-17 (5), to evaluate relationships between the number of CSII users at each centre and: a) mean achieved $\mathrm{HbA} 1 \mathrm{c}$; and b) the percentage of individuals with $\mathrm{HbA1c}$ below $7.5 \%$ (Report available at: https://digital.nhs.uk/data-and-information/publications/statistical/national-diabetes-

audit/insulin-pump-report-2016-17). We found no relationship with number of CSII users and HbA1c outcomes.

Our study has several strengths, one of which being the first UK study to specifically report on the impact of social deprivation on pre- and post-CSII HbA1c levels. Those with higher social deprivation had notably higher baseline $\mathrm{HbA} 1 \mathrm{c}$ levels. However the benefits of CSII therapy were not found to be associated with social deprivation, only with pre-CSII HbA1c and centre. Yearly-averaged pre- and post-CSII HbA1c levels were used to maximise precision in estimating change in glycaemic control. We included a large sample size with wide socioeconomic status (Interquartile range of the Index of Multiple Deprivation from 6312 to 25727). Limitations and caveats include the observational nature of the study, lack of information about hypoglycaemia, ethnicity, psychological status, staffing ratios and number of contacts and clinic visits among pump users in the three centres.

In conclusion, higher pre-CSII HbA1c levels were associated with higher levels of deprivation and being female. We also found significant differences in $\mathrm{HbA1c}$ outcomes with 
CSII between three neighbouring hospitals in Greater Manchester. These differences were not due to social deprivation or commonly measured demographics such as age, sex or duration of diabetes. Although the two centres with better outcomes had more patients who had undertaken structured education, there were no differences in $\mathrm{HbA} 1 \mathrm{c}$ outcomes between those who had undertaken structured education vs. those who have not, after adjusting for deprivation index, pre-CSII $\mathrm{HbA} 1 \mathrm{c}$ and centre. Further work is warranted to understand whether other unmeasured confounders, such as psychological factors may explain these differences. People with type 1 diabetes from deprived backgrounds should be provided with equal access to CSII; there should be more comparisons of outcomes between units providing CSII services.

\section{ACKNOWLEDGMENTS}

Author contributions: JB (UHSM), AP (SRFT), LL Centre (MRI) takes responsibility for the integrity of the data from each centre. LL and CF take responsibility for the accuracy of the data analysis. LL, JB, AP, HT and MKR co-designed the study. AH, TA, JB, AP, AC, JM, AU collected data. CF carried out the data and statistical analyses. HT, MKR, LL, JB, AP contributed to the interpretation of the results. HT and LL wrote the manuscript. All authors critically reviewed the report. No writing assistance was provided. 


\section{References}

1. Pickup JC: Insulin-pump therapy for type 1 diabetes mellitus. N Engl J Med 2012;366:16161624

2. Beato-Vibora P, Yeoh E, Rogers H, Hopkins D, Amiel SA, Choudhary P: Sustained benefit of continuous subcutaneous insulin infusion on glycaemic control and hypoglycaemia in adults with Type 1 diabetes. Diabet Med 2015;32:1453-1459

3. Pickup JC, Sutton AJ: Severe hypoglycaemia and glycaemic control in Type 1 diabetes: meta-analysis of multiple daily insulin injections compared with continuous subcutaneous insulin infusion. Diabet Med 2008;25:765-774

4. Leelarathna L, Roberts SA, Hindle A, Markakis K, Alam T, Chapman A, Morris J, Urwin A, Jinadev $P$, Rutter MK: Comparison of different insulin pump makes under routine care conditions in adults with Type 1 diabetes. Diabet Med 2017;

5. NHS Digital: The National Diabetes Audit Insulin Pump Report 2016-17. https://digital.nhs.uk/data-and-information/publications/statistical/national-diabetesaudit/insulin-pump-report-2016-17

6. Greater Manchester Health and Social Care Partnership: About Devolution. Available at wwwgmhscorguk Last accessed 10/06/2018;

7. Ministry of Housing Communities \& Local Government: English indices of deprivation 2015. Available at https://wwwgovuk/government/statistics/english-indices-of-deprivation-2015 2015:Last accessed 10/06/2018

8. Anyanwagu $U$, Olaoye $H$, Jennings $P$, Ashton-Cleary $S$, Sugunendran $S$, Hughes $D$, Idris I, Wilmot EG: Continuous subcutaneous insulin infusion (CSII) therapy at Derby Teaching Hospitals: sustained benefits in glucose control. Diabet Med 2017;

9. Misso ML, Egberts KJ, Page M, O'Connor D, Shaw J: Continuous subcutaneous insulin infusion (CSII) versus multiple insulin injections for type 1 diabetes mellitus. Cochrane Database Syst Rev 2010:CD005103

10. Szypowska A, Schwandt A, Svensson J, Shalitin S, Cardona-Hernandez R, Forsander G, Sundberg F, De Beaufort C, Maahs D, Maffeis C, O'Riordan SM, Krisane ID, Scharf M, Castro S, Konstantinova M, Obermannova B, Casteels K, Goksen D, Galhardo J, Kanaka-Gantenbein C, Rami-Merhar B, Madacsy L: Insulin pump therapy in children with type 1 diabetes: analysis of data from the SWEET registry. Pediatr Diabetes 2016;17 Suppl 23:38-45 